\title{
Morfologia de frutos, sementes e plântulas de Guettarda platypoda DC. (Rubiaceae)
}

\author{
Liliane Ferreira Lima ${ }^{1}$, Patrícia Barbosa Lima ${ }^{1}$ \\ Eduardo Bezerra de Almeida Jr. ${ }^{1}$ \& Carmen Silvia Zickel ${ }^{2,3}$ \\ ${ }^{1}$ Programa de Pós-graduação em Botânica, Laboratório de Florística de Ecossistemas Costeiros, \\ Universidade Federal Rural de Pernambuco - UFRPE, Recife, PE, Brasil \\ ${ }^{2}$ Departamento de Biologia, Área de Botânica, Universidade Federal Rural de Pernambuco - UFRPE, \\ Rua Dom Manoel de Medeiros, s/n, CEP 52171-900 Dois Irmãos, Recife, PE, Brasil \\ ${ }^{3}$ Autor para correspondência: Carmen Silvia Zickel, email: zickelbr@yahoo.com
}

LIMA, L.F., LIMA, P.B., ALMEIDA Jr., E.B. \& ZICKEL, C.S. Morphology of fruits, seeds and seedlings Guettarda platypoda DC. (Rubiaceae). Biota Neotrop. 10(1): http://www.biotaneotropica.org.br/v10n1/en/ abstract?article+bn02310012010.

Abstract: Morphology of fruits, seeds and seedlings Guettarda platypoda DC. (Rubiaceae). Guettarda platypoda DC., popularly known as angélica, is a shrub of medicinal importance and it has Neotropical distribution. The aim of this work is to characterize morphologically its seeds, fruits and seedlings, adding data to support studies about its utilization and conservation of this specie. Ripe fruits were manually collected from ten matrix trees in the restinga of Maracaípe, stored in identified paper bags, and cooled until processing them in the laboratory. Fresh material was used for morphological analysis of fruits, seeds and seedlings. Fruits of G. platypoda are drups, with only one bilocular pireny, hypocotyl embryo and vestigial cotyledons. Seeds were treated to break dormancy, but even so seedling emergency was slow. Germination is epigeous and the cotyledons are foliaceous. The characteristics of fruits, seeds and seedlings of G. platypoda here described are useful for identification, as well as, to increase knowledge on the its biology.

Keywords: biometrics, morphological description, dormancy, germination, propagating.

LIMA, L.F., LIMA, P.B., ALMEIDA Jr., E.B. \& ZICKEL, C.S. Morfologia de frutos, sementes e plântulas de Guettarda platypoda DC. (Rubiaceae). Biota Neotrop. 10(1): http://www.biotaneotropica.org.br/v10n1/pt/ abstract?article+bn02310012010.

Resumo: Morfologia de frutos, sementes e plântulas de Guettarda platypoda DC. (Rubiaceae). Guettarda platypoda DC., conhecida popularmente por angélica, é uma planta arbustiva, possui importância medicinal e distribuição neotropical. Por serem praticamente escassos trabalhos sobre essa espécie, o presente estudo tem como objetivo caracterizar morfologicamente as sementes, frutos e plântulas, acrescentando dados para subsidiar estudos sobre sua utilização e conservação. Os frutos maduros foram coletados manualmente de 10 árvores matrizes na restinga de Maracaípe, armazenados em sacos de papel-madeira e resfriados até o processamento em laboratório. Foram feitas análises morfológicas dos frutos, sementes e plântulas. Para avaliar o processo germinativo as sementes foram submetidas a tratamentos de quebra de dormência. Os frutos de G. platypoda são drupóides, com apenas um pirênio bilocular, embrião hipocotilar e cotilédones vestigiais. A taxa de germinação apresentou-se baixa, com germinação do tipo epígea e com cotilédones foliáceos. O tipo e as características do fruto, a morfologia da semente e da plântula de G. platypoda contribuem tanto para identificação quanto para ampliar o conhecimento sobre a biologia da espécie.

Palavras-chave: biometria, descrição morfológica, dormência, germinação, propágulos. 


\section{Introdução}

A família Rubiaceae possui distribuição cosmopolita com 550 gêneros e 9000 espécies, sendo 120 gêneros e 2000 espécies encontradas no Brasil, correspondendo a uma das principais famílias de nossa flora, ocorrendo como um importante elemento em quase todas as formações naturais (Souza \& Lorenzi 2008). Para a região Nordeste, Barbosa et al. (1996) compilaram 66 gêneros e 277 espécies presentes na flora. Dessas espécies, inclui-se Guettarda platypoda DC., uma planta arbustiva que apresenta distribuição neotropical (Andersson 1992), ocorrendo em regiões litorâneas do Nordeste (Pereira \& Barbosa 2004), sendo bastante utilizada na medicina popular. Conhecida popularmente como angélica, angélica da praia e angélica do mato, essa espécie ainda é pouco estudada, principalmente no que se refere à morfologia de frutos, sementes e dos estádios iniciais de desenvolvimento.

Segundo Barroso et al. (1999), o estudo do tamanho, forma e tipo de deiscência dos frutos, são caracteres imprescindíveis para a classificação. Ainda segundo os mesmos autores, os estudos morfológicos de frutos contribuem para a identificação das espécies, bem como sua distribuição geográfica e interações com a fauna. Esse tipo de informação pode servir tanto para melhorar a conservação da fauna e da flora, principalmente das espécies que se encontram em via de extinção, quanto contribuir com estudos de sucessão ecológica e regeneração dos ecossistemas florestais (Beltrati 1992).

O estudo dos estádios iniciais da vida da planta também pode oferecer informações importantes sobre o desenvolvimento da espécie, servindo como subsídio para a produção de mudas e permitindo uma melhor compreensão do processo de estabelecimento da planta em condições naturais da floresta (Guerra et al. 2006). Esses dados têm merecido atenção há algum tempo, quer seja como parte de estudos morfo-anatômicos, objetivando ampliar o conhecimento de determinada espécie ou grupamento sistemático de plantas, quer visando o reconhecimento e identificação de plântulas de certa região, dentro de um enfoque ecológico (Oliveira 1993). No entanto, apesar da grande importância dos estudos morfológicos dos frutos, sementes e plântulas, no Brasil ainda são escassos os trabalhos com esse enfoque.

Dessa forma, este estudo tem como objetivo caracterizar morfologicamente as sementes, frutos e plântulas de G. platypoda, acrescentando dados para subsidiar estudos que visem sua utilização e conservação.

\section{Material e Métodos}

\section{Local de estudo}

O estudo foi realizado na Reserva Particular do Patrimônio Natural (RPPN) - Nossa Senhora do Outeiro de Maracaípe. A área localiza-

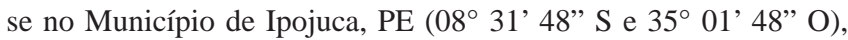
possui aproximadamente 76 ha. de vegetação de restinga. O clima local é do tipo As', segundo o sistema de classificação de Köppen (1948), com precipitação anual de $2000 \mathrm{~mm}$ e período chuvoso ocorrendo entre maio e julho e período seco entre outubro e dezembro (Medeiros et al. 2007).

\section{Coleta, processamento dos dados e classificação sucessional}

Os frutos maduros de G. platypoda foram coletados manualmente de 10 árvores matrizes, sendo acondicionados em sacos de polietileno e transportados ao Laboratório de Florística de Ecossistemas Costeiros (LAFLEC), da Universidade Federal Rural de Pernambuco (UFRPE), onde foram transferidos para sacos de papel-madeira, sendo identificados com o número de coletor e resfriados até serem processados.
O processamento teve início com a biometria e descrição dos frutos, seguido da retirada das sementes. Posteriormente, os propágulos foram pesados em balança digital de precisão (BEL ENGINEERING - Umark 210A), medidos (comprimento e largura) com paquímetro digital (Digimess-100.174BL) e descritos com o auxílio de lupa de mesa estereoscópica (Leica Zoom-2000). Considerou-se para as medidas de comprimento, a distância entre a base e o ápice do fruto e largura, o lado mais extenso.

Para a classificação morfológica e ecológica da espécie foram consideradas as características do fruto, semente e plântula associadas ao peso da semente e observações realizadas em campo. A morfofuncionalidade da plântula foi baseada na proposta de classificação de Miquel (1987) e para o grupo sucessional foi utilizada a proposta de Budowski (1965), que considera quatro grupos principais: pioneiras, secundária inicial, secundária tardia e clímax.

\section{Caracterização morfológica do fruto e da semente}

No laboratório, foram selecionados aleatoriamente 100 frutos e 100 sementes para descrição dos caracteres morfológicos, que se basearam nos trabalhos de Barroso et al. (1999) e Gonçalves \& Lorenzi (2007).

Nos frutos foram observados aspectos relacionados à deiscência, detalhes externos e internos do pericarpo, forma, tamanho, consistência, brilho, pilosidade e número de sementes por fruto, entre outras características eventuais. Para as sementes foram analisados os seguintes caracteres: dimensão, envoltório, tegumento, coloração, textura, consistência, forma, posição do hilo, presença ou ausência de endosperma, características do embrião, cotilédones e eixo hipocótilo-radícula.

\section{Aspectos morfológicos da germinação e da plântula}

Para analisar a germinação e morfologia das plântulas as sementes foram semeadas em bandejas plásticas $(28 \times 15 \times 8 \mathrm{~cm})$ na casa de vegetação. Cada bandeja continha vermiculita expandida estéril e solo da restinga (1:2), que serviu como substrato e meio de retenção de umidade. As bandejas foram irrigadas e a germinação das plântulas acompanhadas diariamente.

Para a descrição morfológica dessas plântulas foram analisados cinco indivíduos (mais vigorosos), a partir de observações diretas resultantes da germinação em casa de vegetação, sendo os elementos descritos os mesmos sugeridos por Roderjan (1983): colo, hipocótilo, cotilédones, epicótilo, eofilo (protofilo) e raiz. As terminologias empregadas basearam-se em Radford et al. (1974), Duke \& Polhill (1981) e Oliveira (1993).

Foram consideradas germinadas as sementes em que as plântulas emitidas chegavam a elevar o hipocótilo ou epicótilo acima do nível do solo (Brown 1992), e foi considerada como plântula o estádio em que os eofilos (protofilos) já estavam totalmente formados (Feliciano 1989).

Para obtenção das plântulas e avaliação do processo germinativo, as sementes foram submetidas a tratamentos de quebra de dormência, as quais foram distribuídas em diferentes amostras, cada uma contendo 50 sementes (Tabela 1), totalizando 700 sementes.

As sementes foram distribuídas em 14 amostras, cada uma sob os diferentes tratamentos: T1 - Utilizou-se sementes intactas, sendo elas a amostra controle; T2, T3 e T4 - Submersas em água por 2, 6 e 48 horas, respectivamente, para facilitar o processo de embebição; T5 e T6 - Escarificação mecânica (lixa e estilete, respectivamente), utilizada para facilitar a saída da radícula e absorção de água; T7, T8, T9, T10, T11 e T12 - sementes submetidas a imersão em ácido acético, para quebrar possível dormência tegumentar; T13 e T14 - sementes submetidas a choque térmico de 50 a $80{ }^{\circ} \mathrm{C}$, respectivamente. 


\section{Resultados e Discussão}

\section{Caracterização morfológica do fruto}

A espécie G. platypoda apresenta frutos drupóides, originados de um ovário bicarpelar, bilocular e ínfero. A forma varia de globosa a elipsóide (Figura 1a), com as dimensões de 5,13-9,90 mm de comprimento e 4,95-12,40 mm de largura. Epicarpo verde-claro quando imaturo e branco-amarelado, quando maduro. A superfície externa do fruto varia de lisa ou com algumas depressões, com tricomas brancos e indumento tomentoso. Mesocarpo carnoso, formando uma polpa suculenta, esbranquiçado, macio, com 1,55-1,94 mm de espessura; sabor adocicado e com odor devido à presença de flavonóides (Corrêa 2007). A polpa formada é de natureza placentar. O

Tabela 1. Listagem dos tratamentos de quebra de dormência utilizados para obtenção das plântulas no presente estudo. sg = sem germinação.

Table 1. List of treatments to break of dormancy used to obtain the seedlings in this study. $\mathrm{sg}=$ no germination.

\begin{tabular}{clc}
\hline Tratamentos & \multicolumn{1}{c}{ Descrição dos tratamentos } & Germinação (\%) \\
\hline T1 & Sementes intactas (controle) & $4 \%$ \\
T2 & Submersas em água durante 2 horas & $4 \%$ \\
T3 & Submersas em água durante 6 horas & $4 \%$ \\
T4 & Submersas em água durante 48 horas & $4 \%$ \\
T5 & Escarificação mecânica com lixa madeira n 60 & $12 \%$ \\
T6 & Escarificação mecânica com estilete (retirada parcial do tegumento) & $12 \%$ \\
T7 & Imersão em ácido acético glacial (P.A.) por 5 minutos & $\mathrm{sg}$ \\
T8 & Imersão em ácido acético glacial (P.A.) por 10 minutos & $\mathrm{sg}$ \\
T9 & Imersão em ácido acético glacial (P.A.) por 15 minutos & $\mathrm{sg}$ \\
T10 & Imersão em ácido acético glacial (P.A.) por 20 minutos & $8 \%$ \\
T11 & Imersão em ácido acético glacial (P.A.) por 25 minutos & $8 \%$ \\
T12 & Imersão em ácido acético glacial (P.A.) por 40 minutos & $8 \%$ \\
T13 & Choque térmico a 50 ${ }^{\circ} \mathrm{C}$ & $\mathrm{sg}$ \\
T14 & Choque térmico a $80{ }^{\circ} \mathrm{C}$ & $\mathrm{sg}$ \\
\hline
\end{tabular}
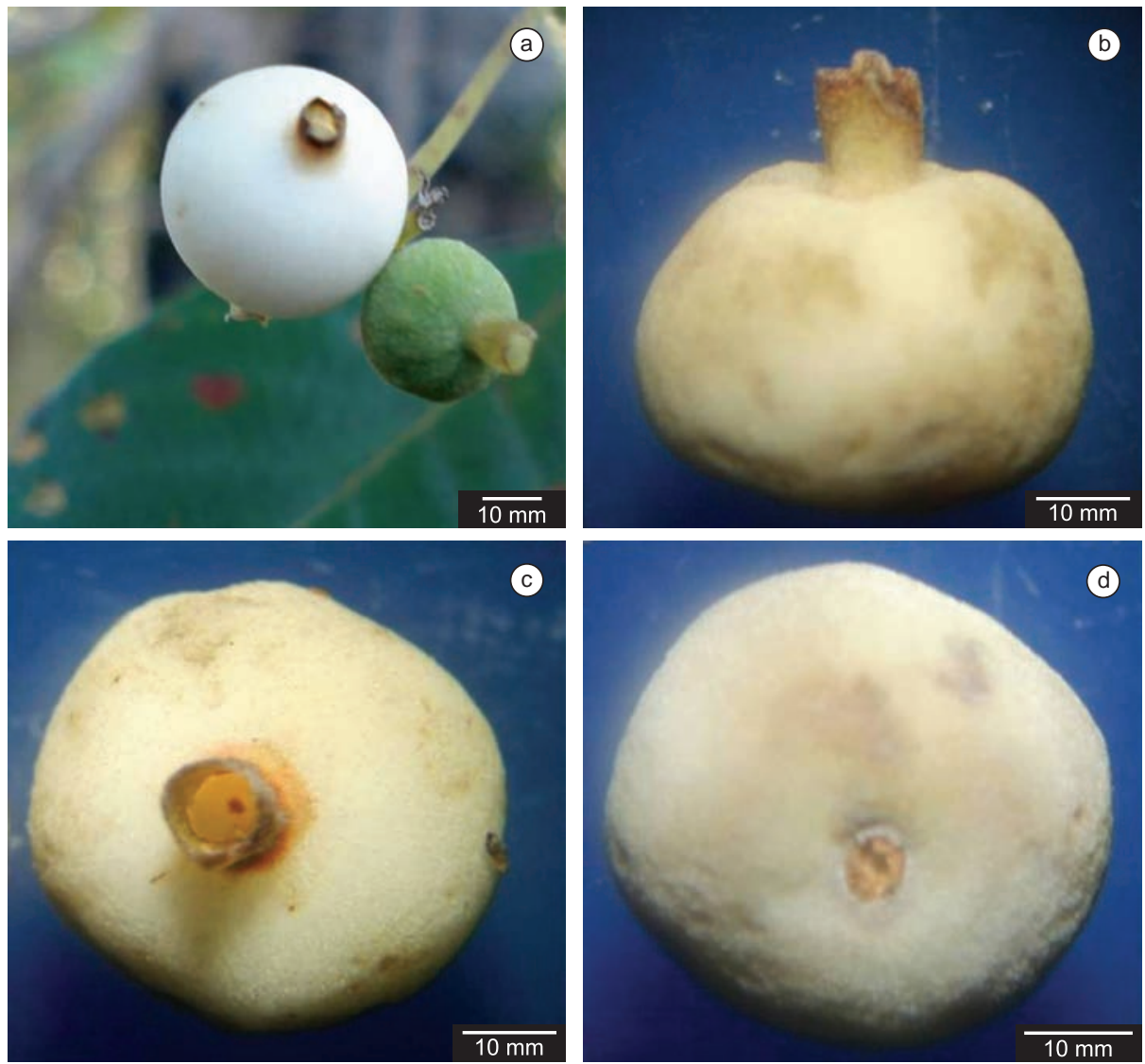

Figura 1. Aspecto morfológico do fruto de Guettarda platypoda DC.: a) Fruto maduro e imaturo; b) Vista longitudinal do fruto; c) Região apical do fruto; e d) Região basal do fruto.

Figure 1. Morphological aspect of the fruit of Guettarda platypoda DC.: a) Mature and immature fruit; b) Longitudinal view of the fruit; c) Apical region of the fruit; and d) Basal region of the fruit. 
endocarpo é lenhoso, formado por uma rede de finas fibras, aderido a semente. $\mathrm{O}$ fruto exibe pedicelo piloso e coloração esverdeada. Cálice floral acrescente e persistente, formando na frutificação uma estrutura pequena e circular na região apical, de coloração marrom (Figura 1b-c).

Os dados acima descritos exibem características peculiares da espécie que podem facilitar o seu reconhecimento e identificação em campo. Barroso et al. (1999) ao descreverem os frutos da família Rubiaceae e do gênero Guettarda relataram que o cálice, quando persistente, pode oferecer alguma ajuda na identificação dos táxons, visto que os frutos da família apresentam características variadas.

\section{Caracterização morfológica e peso das sementes}

As sementes de G. platypoda apresentam dimensões de 2-3 mm de comprimento e 3-5 mm de largura, envolvidas totalmente pelo endocarpo lenhoso, juntos são denominados de pirênio (Barroso et al. 1999), com apenas um pirênio por fruto. O pirênio varia de globoso a semicilíndrico e apresenta externamente coloração branco-amarelada (Figura 2a-b). O tegumento é rígido, lenhoso, dificultando sua abertura para observação do embrião. Internamente, foi possível observar dois lóculos curvos. Externamente aos lóculos observou-se uma massa gelatinosa e macia. Os lóculos são muito próximos, curvos e muitas vezes distribuídos de forma aleatória, o que dificulta a incisão do embrião para observação e estudo. O hilo é ventral, circular e evidente (Figura 2a). O embrião é hipocotilar, curvo, com 1,98-2,77 mm de comprimento, esbranquiçado-translúcido, com eixos hipocótiloradícula bem definidos, cilíndricos e espessados (Figura 2 c-d). Os cotilédones são vestigiais e brancos. Endosperma ausente. $\mathrm{O}$ peso das sementes variou entre $0,1-0,7 \mathrm{~g}$.

\section{Aspectos morfológicos da germinação e da plântula}

Os testes de germinação aos quais a espécie G. platypoda foi submetida não se mostraram adequados, visto que o número de indivíduos germinados foi pequeno, variando de 4 a $12 \%$ nos diferentes tratamentos. As maiores taxas de germinação foram obtidas nos tratamentos com escarificação, com aproximadamente $12 \%$ de indivíduos germinados. Nos tratamentos controle, submersão em água e imersão em ácido acético com tempo superior a 20 minutos foram observados valores de germinação que variaram entre 4 a $8 \%$. Nos tratamentos com imersão em ácido acético em tempo inferior a 20 minutos e no tratamento com choque térmico não houve germinação (Tabela 1). Diante dos dados obtidos, é possível dizer que as sementes da espécie podem apresentar outros tipos de dormência, além de restrições mecânicas, tais como imaturidade do embrião ou embrião dormente. Segundo Popinigis (1985), a presença de um tipo de dormência numa semente não elimina a possibilidade de outros também estarem presentes, sendo necessária, nesses casos, uma combinação de tratamentos para superação de dormência. Isso talvez explique o baixo resultado obtido com os métodos de superação de dormência utilizados nesse trabalho, os quais estavam relacionados a casos de impermeabilidade e restrições mecânicas do tegumento, não excluindo as outras possíveis causas de dormência da semente.

Lorenzi (1992), analisando a espécie Guettarda viburnoides Cham. \& Schltr., considerou que a planta produz anualmente uma grande quantidade de sementes viáveis, no entanto, a taxa de ger-
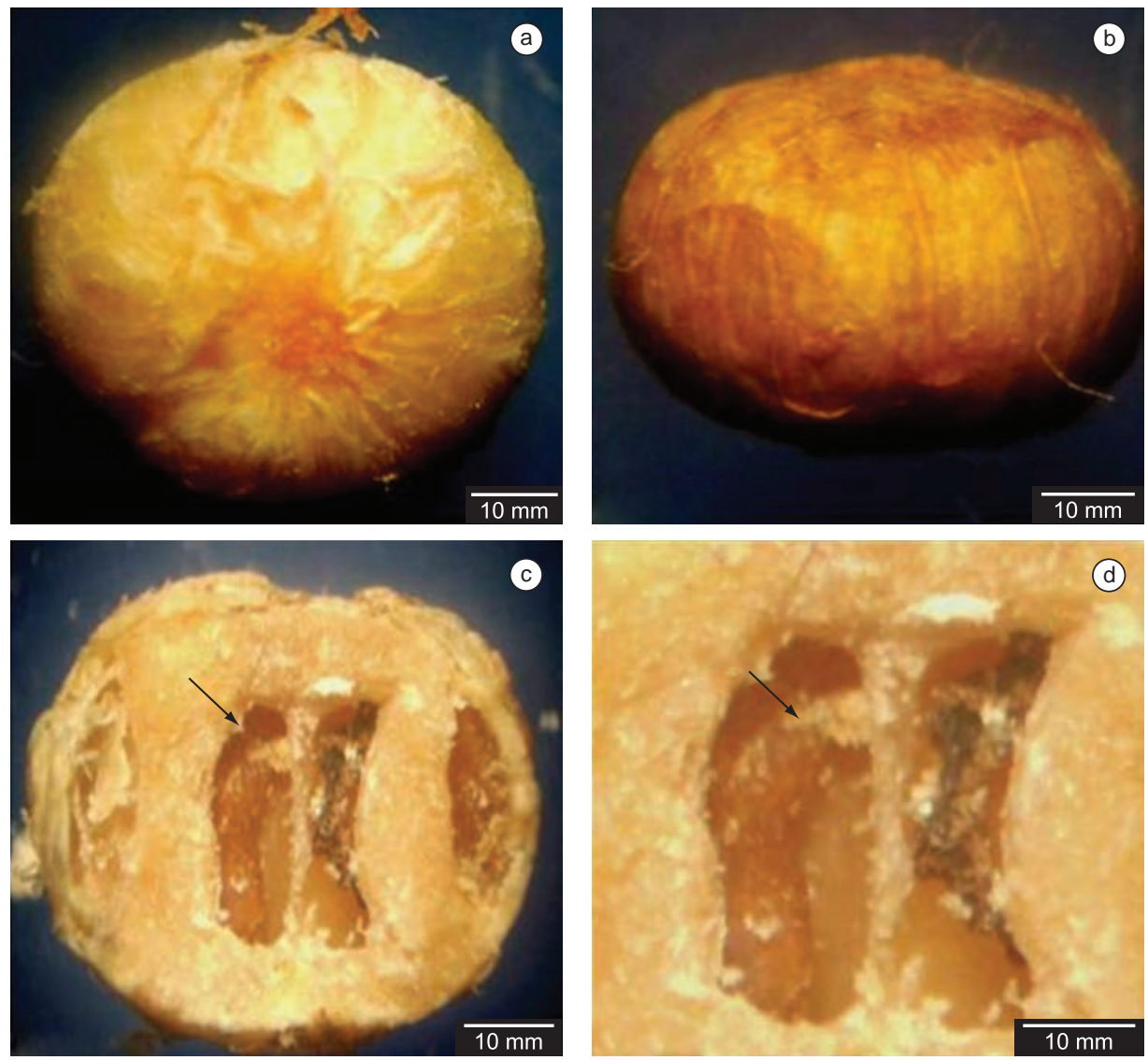

Figura 2. Aspecto morfológico da semente (pirênio) de Guettarda platypoda DC.: a-b) Pirênio; c) Estrutura interna do pirênio, exibindo os lóculos; e d) embrião.

Figure 2. Morphological aspect of seed (pyrene) Guettada platypoda DC.: a-b)Pyrene; c-d) Internal structure of pyrene (locules and embryo). 

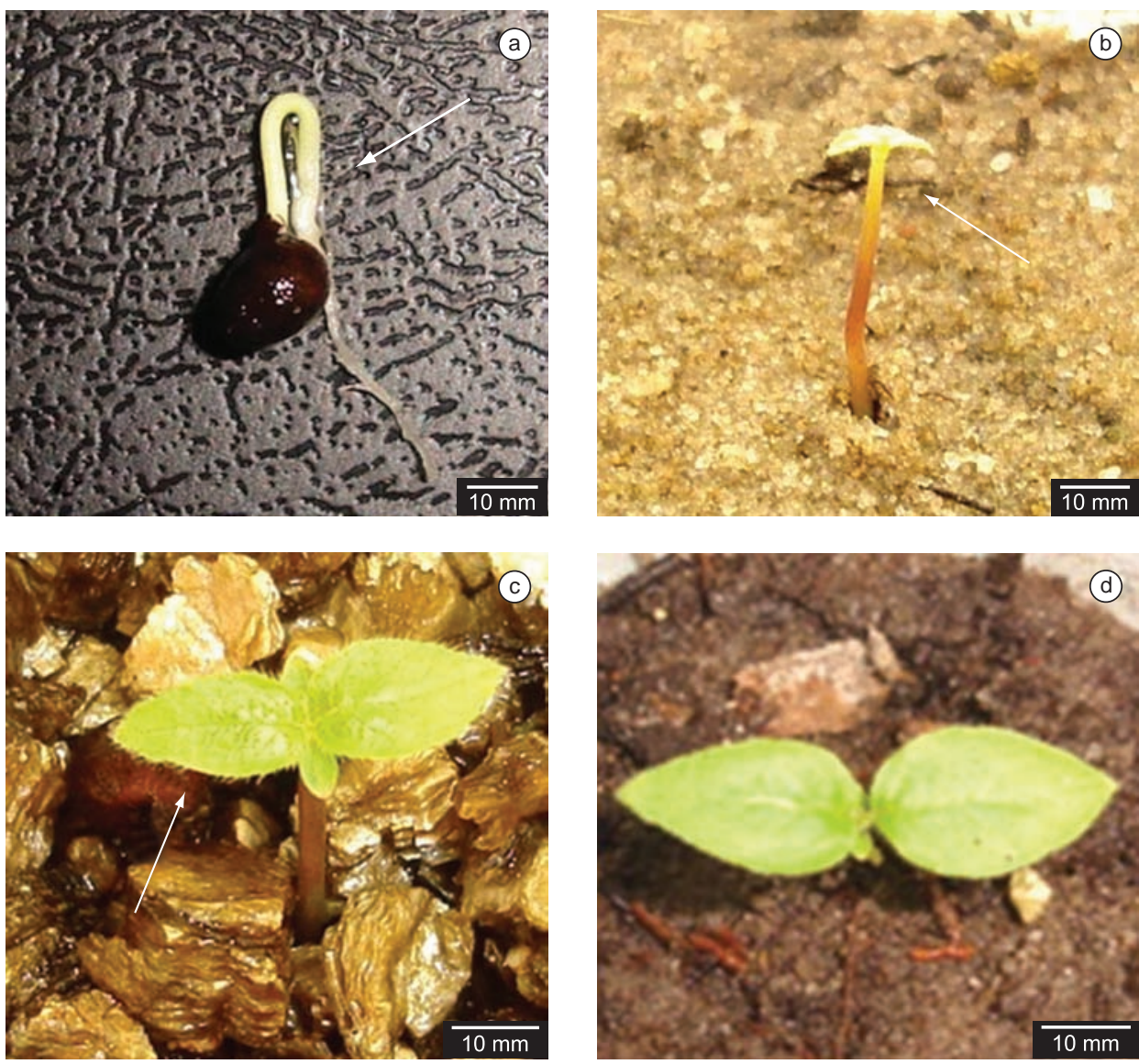

Figura 3. Germinação e plântula de Guettarda platypoda DC.: a) alça hipocotilar; b) posição dos cotilédones; c) formação do primeiro par de eófilos; e d) Eófilos completamente formados.

Figure 3. Germination and seedling of the Guettarda platypoda DC.: a) handle hypocotilar; b) position of the cotyledons; c) formation of the first pair of eophylls; and d) Eophylls fully formed.

minação é baixa e a emergência de plântulas só ocorre depois de 34 - 40 dias após a semeadura. Apesar de se tratar de espécies distintas, porém do mesmo gênero, esses dados foram similares aos obtidos para $G$. platypoda no que diz respeito ao tempo necessário para o início da germinação e baixa taxa de indivíduos germinados. Esses fatores podem dificultar a produção de mudas em grande escala e a elaboração de dados que auxiliem estudos sobre germinação.

Durante o estudo, observou-se que as primeiras manifestações da germinação ocorreram aproximadamente entre a quinta e oitava semana de semeadura (Figura 3a), com a formação da alça hipocotilar. Entre 25 e 29 dias de germinação foi possível descrever as plântulas desta espécie, que apresentaram as seguintes características: A germinação é epígea, fanerocotiledonar; coleto levemente intumescido, evidente, branco, glabro; hipocótilo longo em relação ao epicótilo (20 mm), delgado, branco (região próxima ao coleto), avermelhado (ao longo do comprimento) e verde-claro (região próxima aos cotilédones), cilíndrico, levemente puberulento; cotilédones (Figura 3b) foliáceos, sésseis, simples, opostos, $3 \times 1,5 \mathrm{~mm}$, ovados, ápice agudo, base obtusa, margem ciliada, uninérveos, densamente pilosos, concolor; epicótilo curto ( $2 \mathrm{~mm}$ ), cilíndrico, puberulento, verde-claro; primeiro par de eofilos (Figura 3c-d) curto-peciolados, sem estípulas, simples, opostos-cruzados (em relação aos cotilédones), $16 \times 7 \mathrm{~mm}$, ovados, ápice agudo, base arredondada, margem ciliada, peninérveos, pilosos apenas na região adaxial e na margem, concolor, inodoro, membranáceo; a raiz é axial, delgada, levemente sinuosa, branca, com algumas raízes secundárias e terciárias, finas, curtas, inodoras e sem nodulações.
A partir das análises realizadas, foi possível classificar G. platypoda como uma espécie pioneira, por ser dependente de luz, não ocorrer em sub-bosque e desenvolver-se em clareiras e bordas da floresta. Essas características, associadas ao tipo da plântula (fanero-epígeofoliácea), fornecem um maior embasamento quanto à classificação adotada para a presente espécie como foi apontado nos estudos de Ibarra-Manríquez et al. (2001) e Ressel et al. (2004).

Os caracteres morfológicos do fruto, da semente e da plântula, associadas às observações de campo garantem maior segurança quanto à classificação da espécie, mostrando a importância desse conjunto de informações para categorizar, quanto ao nível sucessional, as espécies vegetais em áreas de restinga. Além disso, faz-se necessário, a realização de mais estudos sobre a germinação das espécies desse gênero, com a aplicação de diferentes técnicas para averiguar seu potencial germinativo e facilitar a produção de mudas, contribuindo para o conhecimento do ciclo biológico, regeneração natural e conservação da espécie.

\section{Referências}

ANDERSSON, L. 1992. A provisional checklist of neotropical Rubiaceae. Scripta Bot. Belg. 1:1-199.

BARBOSA, M.R.V., MAYO, S.J., CASTRO, A.A.J.F., FREITAS, G.L., PEREIRA, M.S., GADELHA, N.P.C. \& MOREIRA, H.M. 1996. Checklist preliminar das angiospermas. In Pesquisa botânica nordestina: progresso e perspectivas (E.V.S.B. Sampaio, S.J. Mayo \& M.R.V. Barbosa, orgs). SBB, Recife, p. 253-415. 
BARROSO, G.M., AMORIM, M.P., PEIXOTO, A.L. \& ICHASO, C.L.F. 1999. Frutos e sementes: morfologia aplicada à sistemática de dicotiledôneas. Universidade Federal de Viçosa, Viçosa, 443 p.

BELTRATI, C.M. 1992. Morfologia e anatomia de sementes. Universidade Estadual Paulista, Rio Claro, p. 1-106.

BROWN, D. 1992. Estimating the composition of a forest seed bank: a comparison of the seed extraction and seedling emergence methods. Can. J. Bot. 70(8):1603-1612.

BUDOWSKI, G. 1965. Distribution of tropical American rain forest species in the light of sucessional processes. Turrialba 15(1):40-42.

CORRÊA, P.G. 2007. Defesas foliares em resposta à herbivoria em espécies lenhosas de restinga, Ipojuca - PE. Dissertação de Mestrado, Universidade Federal Rural de Pernambuco, Recife.

DUKE, J.A. \& POLHILL, R.M. 1981. Seedlings of leguminosae. In Advances in legumes systematics (R.M. Polhill \& P.H. Raven, eds). Royal Botanic Gardens, London, p. 941-949.

FELICIANO, A.L.P. 1989. Estudo da germinação de sementes e desenvolvimento da muda, acompanhado de descrições morfológicas de 10 espécies arbóreas ocorrentes no semiárido nordestino. Dissertação de Mestrado, Universidade Federal de Viçosa, Viçosa.

GONÇALVES, E.G. \& LORENZI, H. 2007. Morfologia vegetal: organografia e dicionário ilustrado de morfologia das plantas vasculares. Plantarum, Nova Odessa, 416 p.

GUERRA, M.E.C., MEDEIROS FILHO, S. \& GALLAO, M.I. 2006. Morfologia de sementes, de plântulas e da germinação de Copaifera langsdorfii Desf. (Leguminosae - Caesalpinioideae). Cerne 12(4):322328.

IBARRA-MANRÍQUEZ, G., RAMOS, M.M. \& OYAMA, K. 2001. Seedling functional types in a lowland rain forest in Mexico. Am. J. Bot. 88(10): 1801-1812.

KÖPPEN, W. 1948. Climatologia: con un estudio de los climas de la Tierra. Fondo de Cultura Economica, México, 478 p.
LORENZI, H. 1992. Árvores brasileiras: manual de identificação e cultivo de plantas arbóreas nativas do Brasil. Plantarum, Nova Odessa, 352 p. (v. 2)

MEDEIROS, D.P.W., LOPES, A. \& ZICKEL, C.S. 2007. Phenology of woody species in a tropical coastal vegetation, northeastern Brazil. Flora 202:235-247.

MIQUEL, S. 1987. Morphologie fonctionnele de plantules d'espèces forestières du Gabon. Bull. Mus. Nat. Hist. Nat. 9:101-121.

OLIVEIRA, E.C. 1993. Morfologia de plântulas florestais. In Sementes florestais tropicais (I.B. Aguiar, F.C.M. Piña-Rodrigues \& M.B. Figliola, orgs). ABRATES, Brasília, p. 175-214.

PEREIRA, M.S. \& BARBOSA, M.R.V. 2004. A família Rubiaceae na Reserva Biológica Guaribas, Paraíba, Brasil: subfamílias Antirheoideae, Cinchonoideae e Ixoroideae. Acta Bot. Bras. 18(2):305-318.

POPINIGIS, F. 1985. Fisiologia de sementes. AGIPLAN, Brasília, 289 p.

RADFORD, A.E., DICKISON, W.C., MASSEY, J.R. \& BELL, C.R. 1974. Vascular plants sistematics. Harper and Row, New York, 877 p.

RESSEL, K., GUILHERME, F.A.G., SCHIAVINI, I. \& OLIVEIRA, P.E. 2004. Ecologia morfofuncional de plântulas de espécies arbóreas da Estação Ecológica do Panga, Uberlândia, Minas Gerais. Rev. Bras. Bot. 27(2):311-323.

RODERJAN, C.V. 1983. Morfologia do estádio juvenil de 24 espécies arbóreas de uma floresta com araucária. Dissertação de Mestrado, Universidade Federal do Paraná, Curitiba.

SOUZA, V.C. \& LORENZI, H. 2008. Botânica sistemática: guia ilustrativo para identificação das famílias de fanerógamas nativas e exóticas no Brasil, baseado em APG II. Plantarum, Nova Odessa, 703 p.

Recebido em 20/07/09

Versão reformulada recebida em 05/03/10

Publicado em 08/03/10 